\title{
RANCANG BANGUN ALAT UKUR SISTEM MONITORING pH, TEMPERATUR, DAN KELEMBAPAN AKUARIUM IKAN HIAS BERBASIS ARDUINO UNO
}

\author{
${ }^{1)}$ Bintara Putra Candra Bareta, ${ }^{1)}$ Alex Harijanto, ${ }^{1)}$ Maryani \\ ${ }^{1)}$ Program Studi Pendidikan Fisika FKIP Universitas Jember \\ Email: bintaraputra70@gmail.com
}

\begin{abstract}
Water quality in the process of ornamental fish cultivation plays an important role in creating an environment of life that is in accordance with the needs of ornamental fish. Acidity $(\mathrm{pH})$ and water temperature are one of the important factors of ornamental fish growth. The purpose of this study is to describe how the design system builds arduino-based humidity and $\mathrm{pH}$ temperature measuring instruments. Review the validity of moisture temperature and water $\mathrm{pH}$. Monitor the humidity temperature and $\mathrm{pH}$ of ornamental fish aquarium water to know the results of the same data with liturgy. This research is a research and development research, conducted in the Laboratory of Physics Education Study FKIP Jember University. The research time was carried out for four months. The samples used in this study were ornamental carp. Based on the analysis of data obtained, it can be concluded that, (1) The work of $\mathrm{pH}$, temperature, and spouting systems based on Arduino Uno is made with sen0161-V2, DS18B20 and DHT-11 sensors and data appearance media namely LCD. (2) Rakaian system is then calibrated to state that the system can be used properly. Calibration includes Arduino-based $\mathrm{pH}$, temperature and Humidity sensor calibration as well as LCD testing. (3) The data that has been found by the researcher and the data in the literature has a match.
\end{abstract}

Key word: water quality, Acidity ( $p H)$, water temperature, arduino-based.

\section{PENDAHULUAN}

Pada awal tahun 1985 hingga sekarang, nilai perdagangan internasional ikan hias selalu mengalami kenaikan. Budidaya ikan hias menjadi salah satu bidang usaha yang semakin naik daun. Harga ikan hias dari hari ke hari semakin meningkat dikarenakan nilai pertumbuhan laba yang mencapai $14 \%$ per tahun (Utami, 2013). Jumlah ikan hias yang diperdagangkan di dunia mencapai 1.600 jenis, di mana 750 jenis di antaranya adalah ikan air tawar. Dalam perdagangan ikan hias global, Indonesia memiliki pangsa pasar sebesar 9,5\%. sedangkan Singapura telah mencapai $22,8 \%$. Dari jumlah tersebut $90 \%$ dari kebutuhan ikan Singapura tersebut disuplai dari Indonesia. Sedangkan negara importir terbesar ikan hias selama ini berturut-turut adalah Amerika Serikat (25,3\%); Jepang (11,6\%); dan Jerman $(9,2 \%)$. Potensi Indonesia yang sangat besar ini dapat menjadi potensi ekonomi yang positif bagi kesejahteraan masyarakat (Anonim, 2010). Maka dari itu kegiatan usaha ikan hias memiliki beberapa keunggulan komparatif, di antaranya bisa dengan modal yang sedikit, dapat dilakukan 
oleh industri rumah tangga, pasarnya tidak pernah jenuh, pengembangan strain baru dapat dilakukan secara indvidu, dan kegiatan usaha ini dapat memberdayakan masyarakat melalui industri kecil yang bermuara pada ekspor.

Kualitas air pada proses budidaya ikan hias berperan penting dalam menciptakan suasana lingkungan kehidupan yang sesuai dengan kebutuhan ikan hias agar mampu memberikan suasana yang nyaman bagi kelangsungan pertumbuhan dan perkembangan ikan hias. Kualitas air pemeliharaan dapat menurun dengan cepat karena sisa pakan, fases dan buangan metabolit. (Ebeling et al., 2006) Sisa metabolisme dan sisa pakan yang mengendap didasar kolam dapat menyebabkan meningkatnya konsentrasi fosfat sehingga perairan menjadi keruh. Semakin keruhnya suatu perairan kolam dapat mengurangi cahaya matahari untuk masuk ke dalam perairan dan dapat menghambat fitoplankton untuk berfotosintesis. Jika hal ini terjadi dapat menurunkan produktivitas perairan dan terjadi penurunan kualitas air (Rahman, 2008).

Derajat keasaman atau $\mathrm{pH}$ yang digunakan untuk menyatakan tingkat keasaman suatu larutan. Larutan disebut asam apabila memiliki derajat $\mathrm{pH}-7$, sedangkan basa memiliki derajat $\mathrm{pH}+7$. Tingkat keasaman larutan mengalami siklus di dalam air, pada derajat keasaman -7 (asam) jamur dan bakteri akan berkembangan biak, dan hasil perkembangbiakan tersebut akan mempengaruhi siklus kehidupan ikan. Derajat keasaman $(\mathrm{pH})$ dan suhu air adalah salah satu factor penting dari pertumbuhan ikan hias (Sitorus, 2017). Sarana utama dalam melakukan aktivitas budidaya ikan hias pada penelitian kali ini akan menggunakan akuarium karena akan lebih mudah untuk mengontrol ikan dan kualitas air dengan lebih teliti. Secara kimia, air
$(\mathrm{H} 2 \mathrm{O})$ terdiri dari ion hydrogen $[\mathrm{H}+]$ dan ion hidroksida [OH-]. Jika konsentrasi hydrogen $[\mathrm{H}+]$ tinggi maka larutan akan bersifat asam sedangkan jika konsentrasi hidroksida [OH-] tinggi maka larutan akan bersifat basa 7 .

Arduino adalah pengendali single-board yang bersifat sumber terbuka, diturunkan dari wiring platform, dirancang untuk memudahkan penggunaan elektronik dalam berbagai bidang terutamanya pada penelitian saya ini.Perangkat kerasnya memilki proses Atmel AVR dan softwarenya memiliki bahasa pemrograman sendiri yang dapat memudahkan aplikasinya. Arduino yang digunakan disertai oleh alat ph meter yang menggunakan tampilan analog. Sedangkan untuk mengetahui informasi suhu saya akan menggunakan alat LM35. Bentuk fisik sensor suhu LM35 menyerupai transistor yang mempunyai 3 kaki yang terdiri dari pin kaki input tegangan positif, output, dan input GND (Ihsanto, 2014). Berdasarkan penjelasan tersebut, maka penelitian ini akan membahas tentang Rancang Bangun Alat Ukur Suhu Dan Ph Air Berbasis Arduino Untuk Mengetahui Karakteristik Suhu-Ph Air Akuarium Ikan Hias.

\section{METODE}

Jenis penelitian ini adalah penelitian eksperimen. Penelitian dilaksanakan di Laboratorium Multimedia Program Studi Pendidikan Fisika FKIP Universitas Jember. Perancangan sensor $\mathrm{pH}$, kelmbapan, dan sensor suhu dengan module sensor $\mathrm{pH}$. Dalam perancangan ini, untuk mengukur $\mathrm{pH}$, kelembapan, dan suhu air digunakan sensor $\mathrm{pH}$ dan sensor suhu. Ketiga sensor ini telah digabungkan dalam suatu module $\mathrm{pH}$, kelembapan dan suhu. Sensor $\mathrm{pH}$ bersifat analog sehigga untuk menggunakanya harus dilakukan kalibrasi untuk medapatkan rumus konversi analog to digital (ADC) sensor 
tersebut. Desain alat ditunjukkan oleh Gambar 1 sebagai berikut.

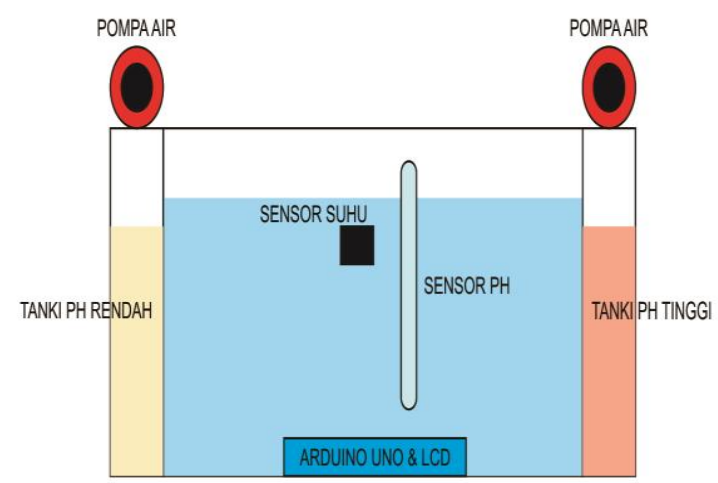

Gambar 1. Desain Alat Arduino

Sampel yang digunakan dalam penelitian ini adalah ikan gurami hias. Kelompok kontrol merupakan kelompok yang tidak diberi perlakuan atau menggunakan alat pabrik, sedangkan kelompok eksperimen menggunakan alat peneliti yang telah di uji coba dengan alat pabrik. Hasil data penelitian ini meliputi pengukuran suhu, nilai $\mathrm{pH}$, dan kelembapan yang masing masing di beri waktu dalam satu peneletian 6 jam, 10 jam, dan 14 jam. Pengambilan data Monitoring $\mathrm{pH}$ dilakukan di kediaman peneliti, pada tanggal 1 - 20 Agustus 2020. Langkah-langkah yang dilakukan dalam penelitian Pengukuran nilai $\mathrm{pH}$ air menggunakan alat $\mathrm{pH}$ meter digital, Pengukuran nilai suhu menggunakan alat Termometer alkohol 110c, sedangkan untuk pengukuran nilai kelembapan menggunakan alat Hygrometer Sebelum semua alat itu digunakan harus dikalibrasi dulu dengan alat yang berupa standart pabrik. Kemudian melakukan Monitoring ke dalam akuarium yang sudah terdapat ikan hias.

\section{HASIL DAN PEMBAHASAN}

1. Hasil Pengujian sensor $\mathrm{pH}$

Hasil pengujian sensor $\mathrm{pH}$ meter didapatkan 3 nilai dari 3 kondisi yang berbeda, yaitu sensor $\mathrm{pH}$ meter dengan keadaan asam, basa, dan netral. Hal ini dapat dilihat pada lampiran B.1 Hasil uji pH meter Arduino dan $\mathrm{pH}$ meter digital. Pengukuran ini dilakukan dengan cara membuat program dasar untuk megkoding $\mathrm{pH}$ meter pada Arduino uno. Program tersebut dikomplikasi dan diuplod pada aplikasi Arduino uno untuk menjalankan $\mathrm{pH}$ meter dan hasil akan tampak pada LCD dari pengukuran $\mathrm{pH}$ meter Arduino. Hasil pengukuran pada tahap ini didapatkan data nilai $\mathrm{pH}$ meter Arduino dan data nilai $\mathrm{pH}$ digital. Alat kalibrasi yang digunakan untuk mengukur $\mathrm{pH}$ yaitu $\mathrm{pH}$ meter standar pabrik (Sensor $\mathrm{pH}$ Daging knife E530BNC). Adapun data percobaan kalibrasi sensor $\mathrm{pH}$ sebagaimana ditunjukkan Tabel 1 berikut:

Tabel 1. Kalibrasi sensor $\mathrm{pH}$.

\begin{tabular}{|c|c|c|c|}
\hline \multicolumn{4}{|c|}{ Kalibrasi Sensor pH } \\
\hline pH & $\begin{array}{c}\text { Percobaan } \\
1\end{array}$ & $\begin{array}{c}\text { Percobaan } \\
2\end{array}$ & $\begin{array}{c}\text { Percobaan } \\
3\end{array}$ \\
\hline Pabrik & 4,73 & 6,33 & 8,63 \\
\hline Buatan & 4,36 & 6,33 & 8,18 \\
\hline Hasil & 4,37 & 6,33 & 7,18 \\
\hline Presentase & $95,64 \%$ & $100 \%$ & $91,82 \%$ \\
\hline
\end{tabular}

Setelah dilakukan pengukuran dengan $\mathrm{pH}$ meter digital, didapatkan data nilai $\mathrm{pH}$, dengan rata rata sebesar $95,64 \%$ asam, $91,82 \%$ basa, dan $100 \%$ netral. Hasil kalibrasi sensor $\mathrm{pH}$ pabrik untuk $\mathrm{pH} 4$ berkisar 4,73, untuk pH 6 berkisar 6,33, dan untuk pH 8 berkisar 8,63. Kalibrasi sensor $\mathrm{pH}$ buatan untuk pH 4 berkisar 4,36, untuk pH 6 berkisar 6,33, dan untuk pH 8 berkisar 8,18. Dari ketiga hasil tersebut dapat dinyatakan bahwa sensor $\mathrm{pH}$ yang telah dirancang bekerja sesuai apa yang diharapkan. Grafk kalibrasi sensor $\mathrm{pH}$ sebagaimana ditunjukkan oleh gambar 2 berikut: 


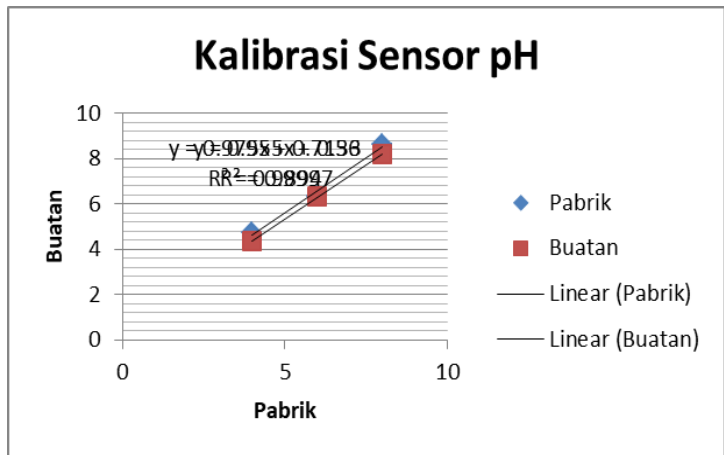

Gambar 2. Grafik Kalibrasi Sensor pH

2. Hasil Pengujian Rangkaian Suhu

Hasil pengujian sensor suhu di dapatak 3 nilai dari 3 kondisi yang berbeda, yaitu sensor suhu dengan keadaan dingin, biasa, dan panas. Hasil uji suhu Arduino dan suhu temperatur. Pengukuran ini dilakukan dengan cara membuat program dasar untuk megkoding Suhu pada Arduino uno. Program tersebut dikomplikasi dan diuplod pada aplikasi Arduino uno untuk menjalankan sensor suhu dan hasil akan tampak pada LCD dari pengukuran suhu. Hasil pengukuran pada tahap ini didapatkan data nilai suhu Arduino dan data nilai suhu termometer. Alat kalibrasi yang digunakan untuk mengukur suhu yaitu alat standar pabrik (Termometer alkohol 110c). Adapun hasil percobaan kalibrasi sensor suhu sebagaimana ditunjukkan Tabel 2 berikut:

Tabel 2. Kalibrasi Sensor Suhu

\begin{tabular}{|c|c|c|c|}
\hline \multicolumn{4}{|c|}{ Kalibrasi Sensor Suhu } \\
\hline Suhu & $\begin{array}{c}\text { Alat } \\
\text { Pabrik }\end{array}$ & $\begin{array}{c}\text { Alat } \\
\text { Peneliti }\end{array}$ & Presentase \\
\hline Percobaan 1 & 21 & 20 & $98 \%$ \\
\hline Percobaan 2 & 28 & 27,56 & $97,25 \%$ \\
\hline Percobaan 3 & 71 & 72,25 & $92,8 \%$ \\
\hline
\end{tabular}

Hasil kalibrasi sensor suhu dingin untuk alat pabrik sebesar 21, untuk alat peneliti sebesar 20, setelah dilakukan pengukuran dengan suhu temperatur, didapatkan data nilai suhu, dengan rata rata sebesar $98 \%$ dingin. Kalibrasi sensor suhu biasa untuk alat pabrik sebesar 28 , untuk alat peneliti sebesar 27,56, setelah dilakukan pengukuran dengan suhu temperatur, didapatkan data nilai suhu, dengan rata rata sebesar $97,25 \%$ biasa. Kalibrasi sensor suhu panas untuk alat pabrik sebesar 71 , untuk alat peneliti sebesar 72,25 , setelah dilakukan pengukuran dengan suhu temperatur, didapatkan data nilai suhu, dengan rata rata sebesar $92,8 \%$ panas. Dari ketiga hasil tersebut dapat dinyatakan bahwa sensor suhu yang telah dirancang bekerja sesuai apa yang di harapkan. Grafik kalibrasi sensor kelembapan sebagaimana ditunjukkan oleh Gambar 3 berikut:

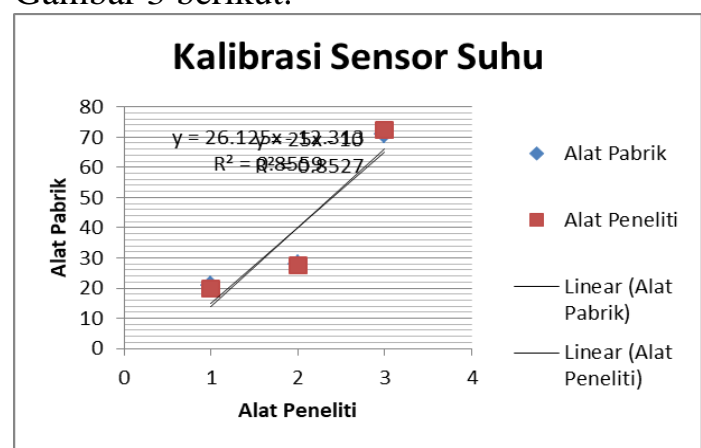

Gambar 3. Grafik Kalibrasi Sensor Suhu

3. Hasil Pengujian Kelembapan

Hasil pengujian sensor kelmbapan di dapatak nilai dari kondisi, yaitu konsentrasi uap air di udara. Hal ini dapat dilihat pada Lampiran B.3 Hasil uji kelembapan Arduino dan kelembapan hygro. Pengukuran ini dilakukan dengan cara membuat program dasar untuk megkoding sensor kelembapan pada Arduino uno. Program tersebut dikomplikasi dan diuplod pada aplikasi Arduino uno untuk menjalankan sensor kelembapan dan hasil akan tampak pada LCD dari pengukuran kelembapan. Hasil pengukuran pada tahap ini didapatkan data nilai kelembapan Arduino dan data nilai kelembapan higrometer. Alat kalibrasi yang digunakan untuk mengukur kelembapan yaitu alat standar pabrik (TFA 45.2007 Analogue Thermometer and Hygrometer). 
Adapun hasil percobaan kalibasi sensor kelembapan ditunjukkan oleh Tabel 3 berikut:

Tabel 3. Kalibrasi Sensor Kelembapan

\begin{tabular}{|c|c|c|c|}
\hline \multicolumn{4}{|c|}{ Kalibrasi Sensor Kelembapan } \\
\hline Jeda waktu & $\begin{array}{c}\text { Alat } \\
\text { Pabrik }\end{array}$ & $\begin{array}{c}\text { Alat } \\
\text { Peneliti }\end{array}$ & Presentase \\
\hline Percobaan 1 & 69 & 69 & $100 \%$ \\
\hline Percobaan 2 & 67 & 66 & $98 \%$ \\
\hline Percobaan 3 & 67 & 67 & $100 \%$ \\
\hline
\end{tabular}

Setelah dilakukan pengukuran dengan kelembapan hygro meter, didapatkan data nilai kelembapan. Pada jeda waktu pertama didapatkan menggunakan alat pabrik sebesar 69, untuk alat peneliti sebesar 69, setelah dilakukan pengukuran dengan kelembapan hygro meter didapatkan data nilai data kelembapan dengan presentase sebesar $100 \%$. Jeda waktu 1 jam didapatkan menggunakan alat pabrik sebesar 67 , untuk alat peneliti sebesar 66, setelah dilakukan pengukuran dengan kelembapan hygro meter didapatkan data nilai data kelembapan dengan presentase sebesar $98 \%$. Jeda waktu 2 jam didapatkan menggunakan alat pabrik sebesar 67, untuk alat peneliti sebesar 67, setelah dilakukan pengukuran dengan kelembapan hygro meter didapatkan data nilai data kelembapan dengan presentase sebesar $100 \%$. Dari hasil tersebut dapat dinyatakan bahwa sensor kelembapan yang telah dirancang bekerja sesuia apa yang di harapkan. Grafik kalibrasi suhu sebagaimana yang ditunjukkan oleh Gambar 4 berikut:

\section{Kalibrasi Sensor Kelembapan}

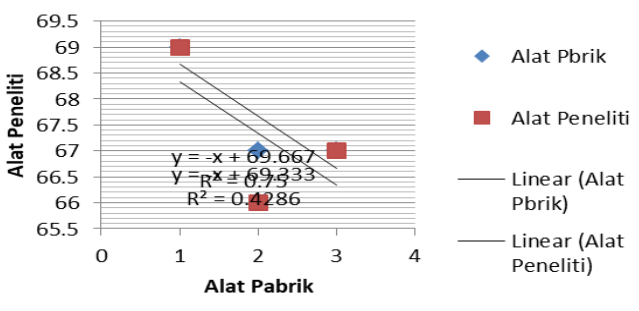

Gambar 4. Grafik Kalibrasi Sensor Kelembaman
4. Hasil Pengujian Rangkaian LCD

Pada pengujian rangkaian LCD ini, dilakukan dengan cara membuat program dasar pada Arduino uno. Program tersebut dikomplikasi dan diupload pada aplikasi Arduino uno. LCD pada baris pertama menampilkan karakter "pH dan Kelembapan" dan baris kedua menampilkan "Suhu". Adapun coding yang dimasukkan pada aplikasi Arduino uno dapat dilihat pada lampiran dan hasil pengujian tampak pada gambar dibawah ini. Berdasarkan hasil pengujian pada gambar tersebut dapat dikatakan pengujian berhasil yang LCD dalam keadaan baik. Hal ini dapat dilihat pada Lampiran B.4 Hasil Pengujian Rangkaian LCD.

\section{SIMPULAN DAN SARAN}

Kerja sistem monitoring $\mathrm{pH}$, Suhu, dan Kelmbapan berbasis Arduino Uno dibuat dengan sensor SEN0161-V2, DS18B20 dan DHT-11 dan media penampilan data yaitu LCD. Cara penggunaanya cukup sederhana, untuk sensor $\mathrm{pH}$ dan air cukup di masukkan ke dalam air sedangkan untuk kelembapan bisa di letakkan d sebelah akuarium saja. Kemudian data nilai pengukuran ditampilkan pada LCD.

Rakaian sistem tersebut kemudian di kalibrasi untuk meyatakan bahwa sistem tersebut dapat digunakan dengan baik. Kalibrasi meliputi kalibrasi sensor $\mathrm{pH}$, suhu, dan Kelembapan berbasis Arduino serta pengujian LCD. Dari hasil kalibrasi tersebut sistem alat dinyatakan berfungsi dengan baik dan dapat digunakan untuk mengukur dengan akurat karena data hasil kalibrasi di bawah $10 \%$, yaitu Di dapat rata - rata kalibrasi alat sekitar $96,6 \%$.

Data yang telah di temukan oleh peneliti dan data yang berada pada literature telah memiliki kecocokan dengan data $\mathrm{pH}$ koi 6,14 , gurami hias 6,60 , cupang 6,26 , berbanding 5,5-7,5, 6,5-8, 6,0-8,0, suhu koi 
$31,81^{\circ}$, Gurami Hias $29,62^{\circ}$, Cupang 28,56 berbanding $30^{\circ}-32^{\circ}, 28^{\circ}-29^{\circ}, 23^{\circ}-38^{\circ}$ dan kelembapan koi 63, gurami hias 64 , cupang 64 berbanding $60-65$.

Adapun saran dalam penelitian ini yaitu diharapkan dapat dijadikan landasan untuk penelitian yang lebih lanjut. Selain itu, dapat dijadikan guru sebagai referensi dalam pembelajaran.

\section{DAFTAR PUSTAKA}

Adhim, G.M 2015. Rancang Bangun Ayunan Bayi dengan Sensor Suara dan Gas Mengunakan Metode Fuzzy. Skripsi. Jember: Fakultas Teknik Universitas Jember.

Adi, A. N. 2010. Mekatronika. 2010. Edisi Pertama. Yogyakarta: Graha Ilmu.

Anonim. 2009. Pengembangan Kawasan Minapolitan. Pedoman Umum. Direktorat Prasarana dan Sarana, Direktorat Jenderal Perikanan Budidaya, $33 \mathrm{hlm}$.

Arfa, M., Suminto., T. Yuniarti. (2017). Pengaruh Ph Media Pemijahan Yang Berbeda Terhadap Persentase Jantan \& Betina Dan Kelulushidupan Ikan Cupang (Betta Splendens Regan). Jurnal of Aquaculture Management and Technology. Vol. 6(3) : 179-186.

Dinata, Y. 2014. Arduino itu mudah. Jakarta: PT Elax Media Komputindo.

Ebeling,J. M., C.F. Welsh, K.L. Rishel. 2006. Performance Evaluationof anInclined Belt Filter Using Coagulation/Flocculation Aids for the Removal of Suspended Solidsand Phosphorus from Microscreen Backwash Effluent. Aquaculture Enginee ring, 35: 6177.
Eltra. B, Andreas Ch, Louk, Redi K. Pinggak. 2018. Otomatisasi Sistem Kontrol pH Dan Informasi Suhu Pada Akuarium Menggunkan Arduino Uno Dan Raspberry Pi 3.

Fitriandi, A., E. Komalasari, dan H.Gusmedi.2016.Rancang bangun alat monitoring arus dan tegangan berbasis mikrokontroler dengan SMS gateway. ELECTRICIAN-Jurnal Rekayasa dan Teknologi Elektro. 10(2) : 93.

Hariati F. S. , Dade J., Mochamad S. 2017 Kelangsungan hidup dan pertumbuhan benih ikan lele (clarias sp.) pada salinitas media yang berbeda. Survival and Growth of Juvenile Catfish (Clarias sp.). Differe Media Salinity Maru.

Hartono, R. 2013. Perancangan Sistem Data Logger Temperatur Baterai Berbasis Arduino Uno Duemilanove. Proyek Akhir. Jember Fakultas Teknik Universitas Jember.

Ihsanto, E. 2014. Rancang Bangun Sistem Pengukuran $\mathrm{Ph}$ Meter Dengan Menggunakan Mikrokontroller Arduino Uno. Jurnal Teknologi Elektro. 5(3):130.

Lintang, E. 2017. Sistem Monitoring Kualitas Air Pada Kolam Ikan Berbasis Wireless Sensor Network Menggunakan Komunikasi Zigbee. Jurnal Teknik Elektro.

Nieveen, N. 2006. Educational Design Research. New York: Taylor and Francis Group. 
Norton N. 2002.sensor and analyzer Handbook. Jakarta : Penerbit Jakarta.

Novitasari A. T. 2017. Rancang Bangun Alat Penggantian Air Dan Pemberian Pakan Secara Otomatis Pada Akuarium Ikan Hias Berbasis Mikrokontroler. Semarang Fakultas Teknik Universitas Negeri Semarang.

Nugraha, S. 2016. Pengaruh Pemberian Hasil Fermentasi Dedak Dengan Ragi Roti Terhadap Parameter Fisika dan Kimia Air Serta Pertumbuhan dan Kelangsungan Hidup Benih Ikan Lele Sangkuriang (Clarias Sp).

Manula, T. 2018. Rancang Bangun Sistem Kontrol pH Air pada Palka Ikan Muatan Hidup menggunakan Mikrokontroler dan LabVIEW. Jurnal Hasil Penelitian dan Industri Terapan. 7(2):56.

Rahman, A.2008. Kajian Kandungan Phospat dan Nitrat Pengaruhnya terhadap Kelimpahan Jenis Plankton di Perairan Muara Sungai Kelayan. Kalimantan Scientiae, 71: 32-44.

Renstra C. G. Tandiogan, dkk. 2017. Rancang Bangun Alat Bantu Mobilitasi Penderita Tunanetra Berbasis Microcontroller Arduino Uno. E-Journal Teknik Elektro dan Komputer. 6(2):80.

Sears dan Zemansky. 2001. Fisika Universitas Edisi Kesepuluh Jilid 1. Jakarta: Erlangga.
Shidiq, Mahfudz. 2008. Pengukur Suhu dan pH Air Tambak Terintegrasi dengan Data Logger. Jurnal EECCIS. 2(1):23.

Siburian, E, dan W, Naibaho. 2014. Laporan PKL. Medan: Universitas HKBP Nomensen.

Silaban, T. F. Santoso, L. dan Suparmono. 2012. Dalam Peningkatan Kinerja Filter Air Untuk Menurunkan Konsentrasi Amonia Pada Pemeliharaan Ikan Mas (Cyprinus carpio). Jurnal e-JRTBP. 1(1):48.

Sitorus, N. B. 2017. Pendeteksian pH Air Menggunakan Sensor pH Meter V1.1 Berbasis Arduino Nano. Sumatra Utara Fakultas Matematika dan Ilmu Pengetahuan Alam Universitas Sumatra Utara

Sugiyono. 2006. Metode Penelitian Pendidikan. Bandung: Alfabeta.

Tirtamihardja S. 1996. Elektronika digital. Yogyakarta : Penerbit Andi Yogyakarta.

Utami, S. W. 2013. Peluang ekspor ikan hias. Jakarta : Penerbit Warta Ekspor.

Umar, E. 2008. Buku Pintar Fisika. Jakarta : Media Pusindo.

Y. A. K. Utama. 2016. Perbandingan kualitas antar sensor suhu dengan menggunakan Arduino pro mini. $e$ Jurnal NARODROID. 2(2). 